\title{
Personality Shaping in Art Design Education
}

\author{
Lingfen Li \\ School of Art and Design \\ Xiamen University of Technology \\ Xiamen, China
}

\begin{abstract}
According to the development status of package design and problems in art design education, the necessity and importance of humanistic care and personality shaping in art design education are proposed. Effective ways and methods of personality cultivation are discussed from the perspective of specialized course teaching. Meanwhile, corresponding suggestions and improvement measures are proposed in this paper.
\end{abstract}

Keywords—art design; package design; humanistic care; personality shaping

\section{INTRODUCTION}

Art design refers to the activity that carries out vision expression of thought or creativity throughout the creation of civilization. With social and economic development as well as scientific and technological progress, art design has been an independent discipline and has become important part in the development of modern society. Nordics regard design as a part of their life. Japanese treat design as means of national existence. Since the reform and opening-up, Chinese universities have provided major of art design, continuously expanding professional fields and improving discipline development. Universities attach great importance to the education in major of art design, having trained numerous professionals. However, for a long time, various reasons especially the negative effects of one-sidedly pursuing material benefits in modern commercial culture make the art design education stay on knowledge level such as skills and practicality. Teaching of specialized course aims at teaching skills and fails to value the formation of students' values and the cultivation of professional ethics. Personality shaping is absent from art design teaching. Art design education trains utilitarian and skilled "utility man" who lack independent personality and professional ethics. Students have professional knowledge and skills instead of humanistic quality and artistic state, lacking value of right and wrong, social responsibility and professional ethics of qualified designers. After graduation, they may follow the herd even play hard to seek number one, let alone guiding sound and orderly development of enterprises or market. Knowledge structure that trains skills has been unable to meet the demands of modern society for high quality designers.

As one of the specialized courses of visual communication design, package design has increasingly sound teaching development, promoting the improvement of package design level and the development of commodity market. However, at present, the overall level of package design is not optimistic. Packaging consciousness, environmental consciousness and humanistic care of package lag far behind that of economically advanced countries. Driven by economic interest, our package design is utilitarian. Commodity packaging becomes important means for enterprises and dealers to pursue high profit. Added value of package is endlessly expanded. Over package and fraudulent packaging are fairly common. Products become insignificant. It misleads the consumer market and violates the principle of environmental protection. In recent years, financial loss and wasting of resources caused by improper packaging is increasingly severe, running counter to the design concept of sustainable development. Meanwhile, employment conflict of packaging becomes increasingly prominent. On one hand, employers of packaging fail to employ qualified packaging talents; on the other hand, students are not willing to work in the front line of packaging production or areas with poor economic benefits. It highlights the problems of package design education in talent training. Absence of personality cultivation leads to the low quality of package designers and the absence of professional ethics, and restricts the sound and sustainable development of package industry. By contrast, in Japan, more attentions are paid to humanistic care and personality shaping in package design. Package design is considered from philosophy, culture and values. Concise and simple packaged forms of MUJI lead the development of design. We must profoundly think about the package design education.

\section{SignifiCANCE OF PERSONALITY CULTIVATION}

\section{A. Personality Cultivation Is the Ultimate Goal of College Education}

Einstein acutely proposes, "The goal of school is that, "young people should be harmonious people instead of experts after graduation", "it is insufficient only to educate professional knowledge... In order to make students understand values and have cordial emotions, they must have discerning power on beauty and morality". Traditional education refers to moral education aiming at "training people". University education in foreign countries puts personality cultivation in the first place. Education is to teach knowledge, shape and improve personality and realize the integrated development of people. Except for professional and innovation ability, excellent designers must have correct value orientation. Except for knowledge and skills, professional teaching should cultivate students' personality in educational concepts, teaching contents 
and teaching methods, in order to make them become qualified citizens with social responsibility and professional ethics.

\section{B. Personality Cultivation Avails Sound Development of Students}

Undergraduates should be new emerging force of social advanced culture. In order to realize social values, except for professional ability, undergraduates major in art design must have perfect personality. Sound personality embodies in three aspects: First, have social responsibility and professional ethics second, have the spirit of forging ahead with determination, having the courage to bring forth new ideas and collaborating wholeheartedly; third, have the quality of modesty, integrity, bearing hardships and standing hard work and perseverance, which are of vital importance on employment and development of students. Big gap exists between reality and ideal. After graduation, students face challenges and employment pressure. The cruel reality causes psychological gap. Undergraduates with independent personality will face challenges bravely, continuously learn and grow in adversity and realize value of life.

\section{The Perfection of Personality Is the Basis of Enterprise Development}

"People" is the most essential element of enterprise development. Occupational qualities of employees directly concern enterprise development. The industrial development of developed countries profits from cultivation of personality and professional ethics. German universities attach importance to training students' comprehensive ability and expressly require students to have "key abilities" including ability to understand professional skills, decision-making ability, independent problem-solving ability, quality awareness, cooperative ability, environmental awareness and social responsibility. Nowadays, many well-known enterprises first consider personality and comprehensive ability of talents instead of employees' scholastic attainment. Except for proficient professional knowledge and skills, more importantly, qualified talents of art design must have sound personality. However, art design education in our country neglects the cultivation of students' personality.

\section{TEACHING OF SPECIALIZED COURSES Is EFFECTIVE WAY OF PERSONALITY CULTIVATION}

First, students' understanding of modern design art and formation of outlook on life and values are immature. Students of design major generally explore professional knowledge and consciously improve professional quality and have ability of independent thinking but ignore even reject character education. Procedural and homiletic moral education has no effects on them. Therefore, the systematic personality cultivation of students should base on professional knowledge, students' pursuit of new fashion, new concept and new technology as well as the development direction of industry. It will convince them and make them form consciousness of deeper level. Second, specialized courses occupy absolute proportion in teaching. Cultivating students' personality through professional teaching is systematic and customary. Although it cannot get effect instantly, with the accumulation of professional knowledge and skills and the improvement of aesthetic consciousness, students will achieve mastery through comprehensive study. It imperceptibly influences the formation of students' outlook on life, artistic view, value and moral behavior. Third, professional teachers contact with students most frequently. Teachers' artistic attainments and moral cultivation have far-reaching influence on the formation of students' personality. Excellent professional teachers have prestige among students because they let students benefit a lot professionally and integrate outlook on life and values in teaching and set good examples for students, enlighten students spiritually through guidance, spiritual communication and personality appeal. The effective personality cultivation greatly relates to teachers' prestige, so professional teachers promote the formation of students' personality.

\section{IMPROVE PERSONALITY SHAPING OF TEACHING IN SPECIALIZED COURSE}

Educator Herbart says, "Without moral education, teaching is only a means without purpose. Without teaching, moral education is a purpose without means". How to implement the education of personality trait in teaching of art design? How to combine professional teaching with personality cultivation to meet demands of modern society? Taking teaching of package design as an example, we carry out through the following aspects:

\section{A. Integrally, Deeply and Orderly Run Humanistic Connotation in Package Design through Design Teaching}

Package design refers to the crossed, comprehensive and commercial art design and the art discipline with humanistic care. Under the premise of protecting goods, promoting consumption and following the trend, package design meets people's physical and psychological pleasure and furthest reflects "people-oriented" ideological connotation. When teaching professional knowledge and skills, teachers should put package design in human development, guide students to explore package design and understand its humanistic background in different eras and regions as well as the formation and evolution of styles and schools. The appreciation and learning of traditional and modern excellent artistic works improve students' aesthetic discernment and independent thinking ability, enhance their professional ability and modern consciousness and make them realize deep meaning and humanistic care of package design through visual principles of package design and presentation of skills, enlighten students to think and design through integral, scientific, speculative and developmental artistic view. For example, when guiding students to learn aesthetic characteristics and professional skills of excellent works of package design in the world, teachers should analyze cultural characteristics especially national characteristics of works, let students realize only the national things are popular in the world. When learning foreign advanced culture, students should absorb national excellent cultural traditions and deeply understand Chinese nationalities, folk culture and symbolic totem, patterns or signs and the philosophical thought of "man is an integral part of nature" and skillfully apply it to actual design. Students prosper Chinese packaging with a sense of national pride and social mission and 
design works of packaging with Chinese national characteristics. Moreover, introducing the latest design dynamics and advanced theory on design makes students systematically grasp current advanced design ideological trend. "Green package" advocates the environmental protection and returning to nature. People urgently need and pursue green food. Because package has the most direct influence on environmental protection, environmental consciousness should be the professional quality of each package designers. Specifically, propose green package and completely eradicate over package and require students to choose natural materials and materials easy to break down as packing materials, such as leaves and stems of plants, thick bamboo tube and terrine. Students must realize social resources are limited. In artistic creation, designers must keep abreast of the development of times, pay attention to living environment and life style of human, care for the weak and guide consumption, serving sustainable development of people through language of design.

\section{B. Help Students to Establish Objectives in Artistic Pursuit of the True, the Good and the Beautiful}

Aesthetically, conforming to the trend and law of social development is the true, conforming to moral principles is the good, objectifying the essential power of the true and the good is the beautiful. Aesthetic function of package bases on "true" utility function of package and "good" social function. The beauty of package design must meet needs of development of times and human development and conform to sound and sustainable social development. In teaching aesthetic function of package design, teachers can neither neglect social and practical functions of package and social ethical norms, nor separate "the beautiful" from "the true" and "the good". Without the inspection of the true and the false, the good and the evil, the inspection of the beautiful and the ugly will not exist, losing social meaning of aesthetics. Teachers must let students realize when providing visual and psychological pleasure for users, good package must conform to social ethical norms and avail sustainable development of people. Instead of pursuing superficial design elements such as modeling, patterns and colors, package design should adhere to people-oriented philosophy and integrate elements at all levels in "design" to analyze and research. According to the analysis the development and change of aesthetic idea in western package design and the understanding of aesthetic standard in traditional Chinese aesthetics, students recognize the relation among "the true", "the good" and "the beautiful" and improve aesthetic consciousness and art taste. Teachers should help students to establish the objectives in artistic pursuit of the true, the good and the beautiful and enrich artistic connotation.

\section{Integrate Personality and Moral Education in Professional Teaching through Various Teaching Forms}

1) Teach students the idea of "behave before learning artistic skills".

Knowledge teaching, ability cultivation and quality improvement should be integrated. For example, when guiding students to do homework, teachers should combine professional training with the cultivation of students' learning attitude and require students to seriously and patiently treat each detail. Meanwhile, correct and adjust students' mind and character through training of skills in package design, help students establish the idea of bearing hardships and standing hard work, and honesty and trustworthiness, rigorous work style and attitude.

\section{2) The life of art design is innovation.}

Teacher-oriented teaching method goes against the cultivation of students' independent will and innovation ability. American A.J. Prose thinks, "Design education is not to create designers but to liberate and help them to know well about themselves and excavate intelligence and wisdom, provide space of imagination and creativity as well as opportunities". The teaching of package design should be student-oriented and strengthen independent, practical and experiential learning state. For example, in teaching professional design course, teachers can inform students about contents and schedule of course in advance to let them have sufficient preview and preparation, organize them to analyze and discuss key points and encourage them to present ideas. Furthermore, according to demands of courses, creative practice is proposed. Students are encouraged to participate in design competition and practice, collect materials to analyze, find and solve problems, carry out artistic creation, absorb and digest new knowledge. It expands students' scope of professional knowledge and horizon and way of thinking and avails the cultivation of students' ability of independence and innovation.

3) In the ever-changing information era, the idea of ultraindividualism has fallen behind the development of times.

Teamwork, communication and coordination and cooperation will be inevitable forms in the future. When encouraging personality development, teachers should train students' collaboration ability and team spirit. For example, as for difficult and complicated practice, teachers group students freely and determine procedure of assignment through group discussion. Students choose one-way target according to their ability and expertise and finish the design project. Teachers guide and coordinate in the process. Students give full play to their specialties and learn from others' strong points to offset their weakness. It exercises students' organizing ability, collaboration ability and ability of independent thinking and greatly improves the quality of work.

4) Lead students to enterprises and carry out on-the-spot teaching or practice.

Students contact advanced professional application and feel the difference between major and industry through social practice. It deepens students' understanding of development trend and codes of practice of this major and strengthens the cultivation of their manipulative ability. Meanwhile, training of professional ethics can be provided for students according to characteristics of enterprises.

\section{CONCLUSION}

To sum up, "people" fundamentally drive social development. Both traditional Chinese education and university education in foreign countries regard personality cultivation as ultimate goal of education. Art design education in universities cannot become "technical education" driven by economic benefits that shake the fundamental of "education", 
namely personality shaping. Teachers should neither onesidedly pay attention to the teaching of professional skills nor neglect or abandon humanistic education, the foundation of sound and sustainable social development and the important mission of teachers.

\section{REFERENCES}

[1] Zhai Yan, Humanistic Quality Education of Contemporary Art Designers, China Adult Education, September 2009

[2] Zhang Chongtian, Discussion on the Concept of Package Design from the Perspective of Humanistic Care, Mass Literary Magazine, February 25,2012 